MPIKG Public Access

Author Manuscript

Published in final edited form as:

Zhang, G., Li, G., Heil, T., Zafeiratos, S., Lai, F., Savateev, A., et al. (2019). Tailoring the grain boundary chemistry of polymeric carbon nitride for enhanced solar hydrogen production and $\mathrm{CO} 2$ reduction. Angewandte Chemie International Edition, 58(11), 3433-3437.

\title{
Tailoring the Grain Boundary Chemistry of Polymeric Carbon Nitride for Enhanced Solar Hydrogen Production and $\mathrm{CO}_{2}$ Reduction
}

\author{
Guigang Zhang, Guosheng Li, Tobias Heil, Spiros \\ Zafeiratos, Feili Lai, Aleksandr Savateev, Markus \\ Antonietti, and Xinchen Wang
}

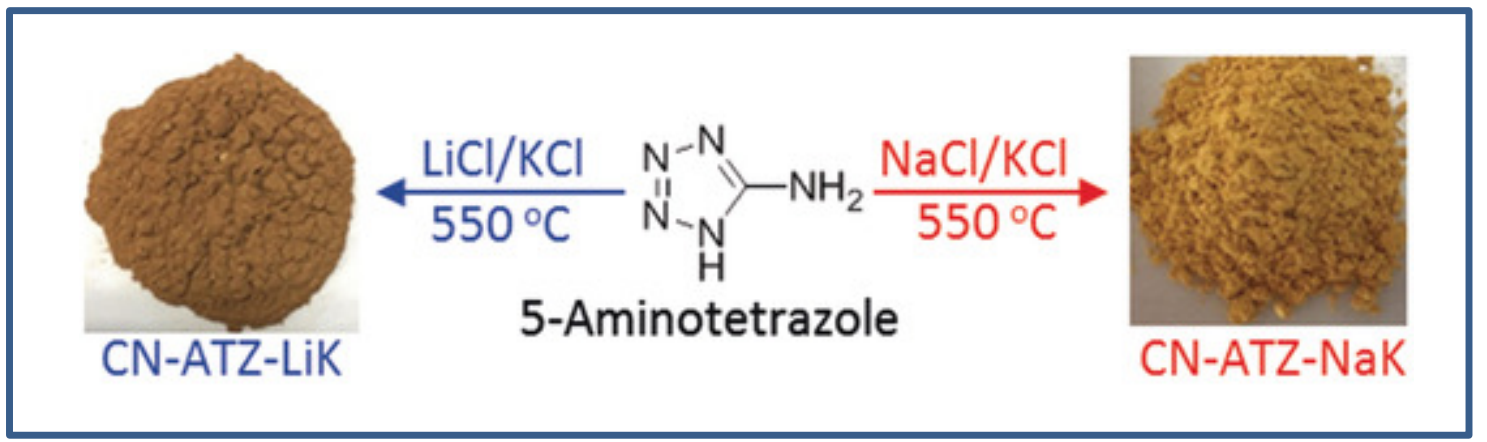

Polymeric carbon nitride with enhanced optical absorption and photocatalytic activities is synthesized via a one-pot ionothermal polymerization of 5 -aminotetrazole in eutectic $\mathrm{NaCl} / \mathrm{KCl}$. This approach allows control of the polymerization process and tailoring of the grain boundary structure and catalytic properties.

This article may be used for non-commercial purposes in accordance with Wiley Terms and Conditions for Self-Archiving. 


\title{
Tailoring Grain Boundary Chemistry of Polymeric Carbon Nitride for Enhanced Solar $\mathrm{H}_{2}$ Production and $\mathrm{CO}_{2}$ Reduction
}

\author{
Guigang Zhang, ${ }^{*}$ Guosheng Li, Tobias Heil, Spiros Zafeiratos, Feili Lai, Aleksandr Savateev, Markus \\ Antonietti, and Xinchen Wang*
}

\begin{abstract}
Photocatalytic water splitting is a promising and clean way to mimic the plant photosynthesis in a sustainable manner. Improvements of the quantum efficiency and optical absorption in the relevant range are certainly the further steps to approach practicality. Here, we reported that these issues can be readily addressed when 5-aminotetrazole, a monomer with still higher nitrogen content, is used for the synthesis of carbon nitride. The molten salt mixture $\mathrm{NaCl} / \mathrm{KCl}$ is used as a high temperature solvent to tailor the grain boundary structure and chemistry. Visible light quantum efficiency for $\mathrm{H}_{2}$ production of 0.65 could be obtained in the presence of $\mathrm{K}_{2} \mathrm{HPO}_{4}$ as double layer modifier. This value is very high considering that this number is a convolute of light to charge couple conversion, charge localization, as well as a successful oxidation and reduction reaction.
\end{abstract}

The worldwide and irreversible consumption of traditional fossil fuels induces severe environmental issues, such as global warming or acidification of the oceans. One of the feasible ways to reduce $\mathrm{CO}_{2}$ emission is to develop carbon-neutral fuels, which must be sustainable, low cost, and storable. Considering that the solar energy irradiating the surface of the Earth $\left(1.3 \times 10^{5}\right.$ TW exceeds the current energy consumption by humankind (22 TW) ${ }^{[1]}$ it is a straight thought to utilize sunlight as alternative source to substitute the fossil feedstock. Photocatalytic water splitting is a simple model reaction to show how low-density solar energy can be converted into storable and high-density chemical energy, e.g., $\mathrm{H}_{2}{ }^{[2-5]}$. As such devices are to compare with the lifetime of a solar panel; it is a serious challenge to develop super-robust, low-cost and sustainable photocatalysts with high efficiency.

To achieve high quantum efficiency, the semiconductor should be able to capture visible photons and generate hot electronhole pairs which have to localize at the catalysts surface in an efficient manner. Different to most of the traditional metal-based semiconductors, polymeric carbon nitride (PCN) was found in recent years to be a very promising choice for all these questions, owing to its advantages as being metal-free, chemically very stable, and possessing a suitable band structure for visible light photocatalysis. ${ }^{[6-11]}$ Early versions of PCN started

- $\quad$ Dr. G. Zhang, Dr. T. Heil, F. Lai, Dr. A. Savateev, Prof. M Antonietti Max Planck Institute of Colloids and Interfaces,

Potsdam, 14476, (Germany)

E-mail: quigang.zhang@mpikg.mpg.de

- G. Li, Prof. X. Wang

State Key Laboratory of Photocatalysis on Energy and Environment,

College of Chemistry, Fuzhou University

Fuzhou, 350116, (China)

Email: xcwang@fzu.edu.cn

- Dr. S. Zafeiratos

ICPEES, Institut de Chimie et des Procédés pour l'Energie,

l'Environnement et la Santé, UMR 7515 CNRS/Université de Strasbourg, 25 rue Becquerel, 67087 Strasbourg cedex, France.

Supporting information for this article is given via a link at the end of the document. with only moderate activities for photocatalytic water splitting This is because as a prototypical polymer, local structure was rather disordered and the exciton binding energy is high, both resulting in inefficient charge transfer to surface.$^{[12]}$ Besides, although visible light active, pristine $\mathrm{PCN}$ can only absorb photons below $460 \mathrm{~nm}$, which massively restricts solar hydrogen production. In the past decade, persistent efforts have been made to modify the structure, properties and activities of PCN. For example, strategies like copolymerization, ${ }^{[13]}$ nanostructure engineering, ${ }^{[14]}$ doping ${ }^{[15]}$ and heterojunction design ${ }^{[16]}$ have been affirmed available to improve the activities. However, more feasible modifications and further improvement of the activities is a continued effort.

Recently, a salt melt-based strategy has been developed to homogenize, but also modulate the polymerization process of PCN. Starting materials, such as melamine and dicyandiamide, were directly mixed with $\mathrm{LiCl} / \mathrm{KCl}$ and heated in a sealed quartz glass tube, providing an inert liquid environment due to a comparably low melting points $\left(\mathrm{mp}=352^{\circ} \mathrm{C}\right)$ but strong monomer solvation, thus resulting in high crystalline carbon nitride. ${ }^{[17]}$ Interestingly, this material was inactive for photocatalytic applications, and poly-triazine-imide (PTI) was found to be the major component under such salt melt conditions. The problem of inactivity was addressed by a two-step modification of the synthetic process, which generated a very active PCN with semi-crystalline structure. Precursors were first heated to obtain the polymeric melon, which was then subsequently mixed with $\mathrm{LiCl} / \mathrm{KCl}$ and further heated in inert atmosphere to improve local structure order and crystallinity in the liquid salt melt. ${ }^{[18]}$ In this case, the first formed heptazines stayed intact, and crystalline poly-heptazine-imide $(\mathrm{PHI})$ rather than $\mathrm{PTI}$ became the major component, which was proven to be extremely stable and very active for photocatalytic reactions. In our own recent research, we found that the $\mathrm{NaCl} / \mathrm{KCl}$ mixture, even though with higher melting points $\left(\mathrm{mp}=650{ }^{\circ} \mathrm{C}\right.$ ), is also a good medium to replace $\mathrm{LiCl} / \mathrm{KCl}^{\left[{ }^{[19]}\right.}$ Obviously, moderate solubility of the $\mathrm{CN}$-educts and products lowers the melting and allows the polymerization to be conducted in an elegant manner. It is believed that the thermodynamically stable K-PHI allotrope is created. No inactive PTI was found under this salt melt condition. Direct cooking of melon in molten salts obviously enables structure rearrangements and improves crystallization, thus enhances the $\pi-\pi^{*}$ electron transitions in the solid.

Following an argument given for the development of "noble carbons" that more electron poor monomers can only polymerize to the most stable polymers, ${ }^{[20]}$ further improvements of the synthetic process should involve more demanding monomers. In this study, we report that 5 -amino-tetrazole (ATZ), an alternative monomer with higher nitrogen content than melamine, urea, and dicyanamide and has recently been used for the synthesis of mesoporous $\mathrm{C}_{3} \mathrm{~N}_{5}$, ${ }^{[21 \text { a] }}$ can be used as a precursor for direct ionothermal synthesis of a PHI-based material. Two different of molten salts, i.e., $\mathrm{LiCl} / \mathrm{KCl}$ and $\mathrm{NaCl} / \mathrm{KCl}$, were selected to prepare $\mathrm{PCN}$ because of their promising properties such as 
lower melting points and robust stability, which are regarded to generate PCN with promising structure and properties. Note that the reaction could be simplified into one step (see Scheme 1). It will be shown below that the $\mathrm{PCN}$ synthesized in $\mathrm{NaCl} / \mathrm{KCl}$ in such way shows much higher activities than that obtained from $\mathrm{LiCl} / \mathrm{KCl}$

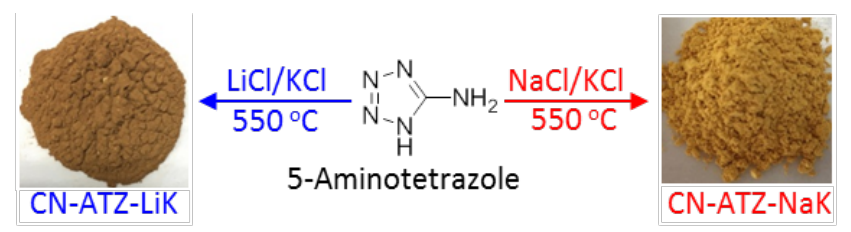

Scheme 1. Proposed one-pot synthesis of CN-ATZ-LiK or CN-ATZ-NaK from 5 -Aminotetrazole in $\mathrm{LiCl} / \mathrm{KCl}$ or $\mathrm{NaCl} / \mathrm{KCl}$ eutectic mixture.

Briefly, samples prepared in the presence of $\mathrm{NaCl} / \mathrm{KCl}$ and $\mathrm{LiCl} / \mathrm{KCl}$ was respectively denoted as $\mathrm{CN}-\mathrm{ATZ}-\mathrm{NaK}$ and $\mathrm{CN}$ ATZ-LiK. For comparison, polymers prepared in the absence of molten salts or in the presence of single salts, i.e. $\mathrm{KCl}$ and $\mathrm{NaCl}$, were labelled as CN, CN-ATZ-K, and CN-ATZ-Na for simplify.

In the first set of examinations, powder XRD, FT-IR, solidstate $C^{13}$ NMR spectra, and high resolution XPS analysis are conducted to examine the chemical structure of the as-prepared $\mathrm{CN}$ samples. As shown in Figure 1a and Figure S1, almost no peak at $\sim 8^{\circ}$ and only one broad peak centred at $27.4^{\circ}$ is found for the CN-ATZ-Na, CN-ATZ-K and CN-ATZ-NaK, which is quite different from CN-ATZ-LiK with narrow and strong diffraction peak. The absence of peak at $\sim 8^{\circ}$ is presumably because of the partial structural transformation from heptazine to triazine under given synthetic conditions and leading to disorder in local structure. ${ }^{[19]}$ The reason for this peak broadening is discussed in context with HRTEM below, but is not to be mistaken with low local order of the covalent network. It should be noted that no peaks which belong to PTI (small peaks of it appear in CN-ATZLiK), was observed for CN-ATZ-NaK. This is probably because the salt melt with higher melting sets in presumably after the heptazine rings already have formed, and a structure transformation from the usually thermodynamically stable heptazine to the less stable triazine is not possible.$^{[17,19]}$ Note that the (100) peak of CN-ATZ-LiK shows up at a lower angle of $8.2^{\circ}$, which was previously ascribed to the integration of $\mathrm{K}^{+}$ between the heterocylic units. ${ }^{[21]}$ Single salts, that is, $\mathrm{NaCl}$ and $\mathrm{KCl}$, can merely improve the structure (Figure S1). This is because of the much higher melting points $\left(\mathrm{KCl}: 770{ }^{\circ} \mathrm{C}\right.$ and $\mathrm{NaCl}: 801^{\circ} \mathrm{C}$ ) which then cannot provide a solution environment under the synthetic conditions $\left(550{ }^{\circ} \mathrm{C}\right)$. FT-IR (Figure S2) also provides evidence that triazine/heptazine structure with few amounts of uncondensed surface cyanogroups are obtained under salt-melt matrix. Except for the lower vibration intensity of surface uncondensed cyanogroups at $2200-2300 \mathrm{~cm}^{-1}$ of $\mathrm{CN}$ ATZ-LiK (owing to the lower melting points of $\mathrm{LiCl} / \mathrm{KCl}$ ), no evident change in the breathing and stretching mode were observed. Solid-state $C^{13}$ NMR spectra (Figure S3) further confirms that both CN-ATZ-LiK and CN-ATZ-NaK are mainly composed with $\mathrm{C}(\mathrm{e})$ atoms $\left(\mathrm{CN}_{2}\left(\mathrm{NH}_{\mathrm{x}}\right)\right)$ and $\mathrm{C}(\mathrm{i})$ atoms of tri-s- triazines $\left(\mathrm{CN}_{3}\right)$. The chemical shifts of CN-ATZ-LiK are shifted slightly to higher fields, indicating a better degree of condensation and delocalization in the resulting frameworks owing to the faster mass transfer in fluid salt mixture. High resolution XPS analysis provides more structural information of the polymers. As shown in Figure S4, both of the two samples are composed of $\mathrm{C}, \mathrm{N}$ and little amounts of $\mathrm{K}(\mathrm{Na})$. The high resolution XPS of N1s in Figure $1 \mathrm{~b}$ can be deconvoluted into three peaks. The major peak located at $398.2 \mathrm{eV}$ is attributed to the $\mathrm{sp}^{2}$ hybridization of $\mathrm{N}$ in the form of $\mathrm{C}-\mathrm{N}=\mathrm{C},{ }^{[18]}$ while the smaller one centred at $400.7 \mathrm{eV}$ is related to the tertiary nitrogen $\mathrm{N}-(\mathrm{C})_{3}$ (or surface primary/secondary amine $\mathrm{C}-\mathrm{N}-\mathrm{H}_{\mathrm{x}}$ ) of the heptazine group as shown in Figure $1 \mathrm{~b}$ inset. The experimental ratio of these two nitrogen species is determined as 7 and 4.5 of the two samples. Obviously, some uncondensed surface amino groups, speaking either for a high specific surface area or -more probably- grain boundaries. The higher ratio of CN-ATZ-NaK indicates more extended condensation and less grain boundaries.
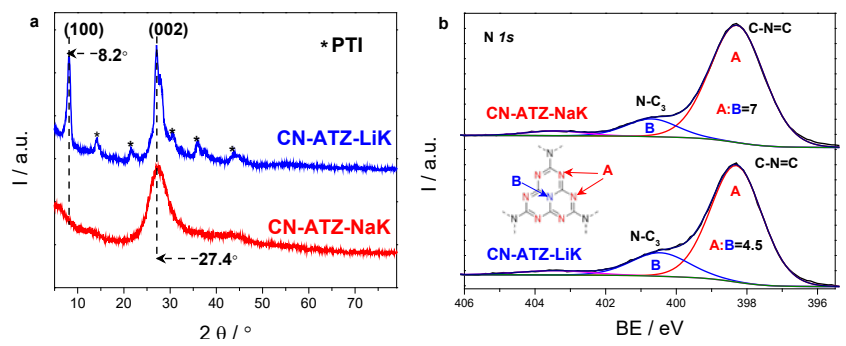

Figure 1. (a) Powder XRD patterns and (b) High resolution N1s XPS analysis of CN-ATZ- LiK and CN-ATZ-NaK polymers.

The different salt media are also reflected in the morphology of the (semicrystalline) polymers. SEM images in Figure S5 show that CN-ATZ-LiK exhibits a reduced particle size and a highly-ordered, crystal-like particle distribution, while those samples prepared from single salts only show a wrinkled bulk structure. CN-ATZ-NaK shows a coexistence of delaminated sheets and bigger stacks which are rough at their surfaces. The specific surface areas of the materials were determined as 4,15 and $17 \mathrm{~m}^{2} \mathrm{~g}^{-1}$ for CN, CN-ATZ-NaK and CN-ATZ-LiK (Figure S6). This fact excludes that neither the lower amount on amine groups nor the significantly increased activity is related to the specific surface area.

To gain more structural details, HRTEM was then carried out for the as-prepared polymers. As shown in Figure 2a, b and Figure S7, both CN-ATZ-LiK and CN-ATZ-NaK present high local order and crystallinity when compared with previously reported amorphous PCN. The crystallinity of CN-ATZ-NaK up to hundreds of nanometers within each sheet goes well with the performance and photophysical properties of the material. Bigger stacks however look more disordered, i.e. we have to assume a turbostratic order in the z-direction, the stacks simply do not register well on show either packing polytypes or even rotational disorder, which also explains the apparent difference of HRTEM and XRD. We have to assume that under the given salt melt conditions, growth in the $\mathrm{x}, \mathrm{y}$-planes is fast and rather 
well organized, while z-plane packing obviously occurs later and then hindered by the size of the preformed sheets.

Typically, the average lattice fringe distances were calculated as 0.89 and $0.31 \mathrm{~nm}$ for CN-ATZ-NaK, which corresponds to the repeating packing distance of heptazine units (100) of $P C N$ in the plane and a irregular ordered graphitic layer stacking distance (002); note that z-ordered carbon nitrides pack with about $0.316 \mathrm{~nm}$ distance. Electron energy loss spectrum (EELS) provides more structure details of the samples. In Figure $2 \mathrm{c}$, no evident difference in both $\mathrm{C}-\mathrm{K}$ and $\mathrm{N}-\mathrm{K}$ edges were found for CN-ATZ-LiK and CN-ATZ-NaK, except for a minor positive shift of the binding energy by $1.2 \mathrm{eV}$, which we attribute to the better crystalline packing and extended conjugation of the heterocycle owing to the lower melting points. ${ }^{[1]} \mathrm{C}-\mathrm{K}$ and $\mathrm{N}-\mathrm{K}$ edges of the samples were then further investigated by $\mathrm{X}$-ray absorption near edge structure (XANES). As shown in Figure 2d and Figure S8, these two samples also show similar spectra in both $\pi^{*}$ and $\sigma^{*}$ region. This further confirms that different salt melt modifications change mainly the local packing, crystallinity and grain boundaries rather than the skeleton structure of the polymers.
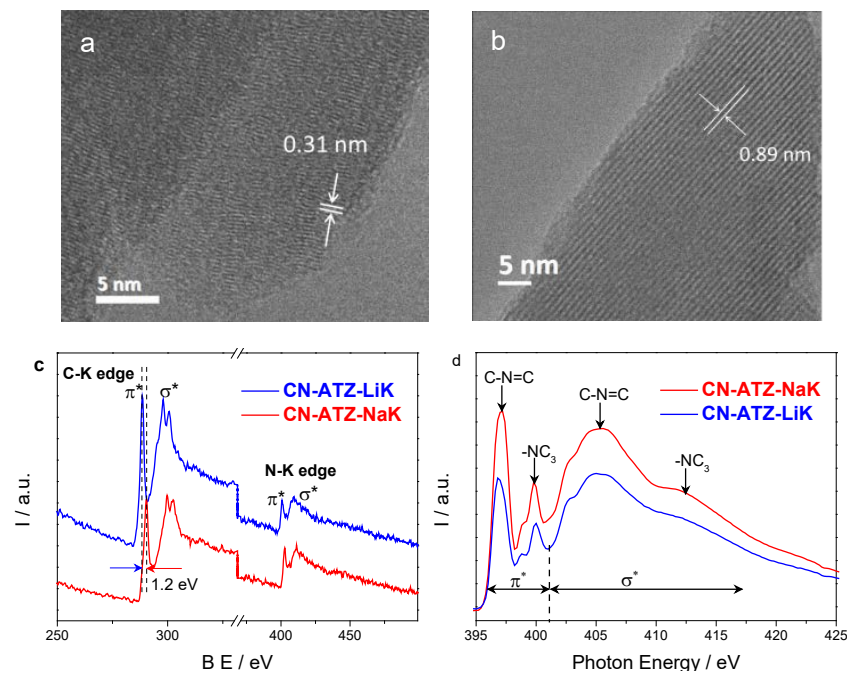

Figure 2. (a) Transition electron microscopy (TEM) and (b) HR-TEM images of CN-ATZ-NaK; (c) Electron energy loss spectra (EELS), and (d) N-K edge XANES of CN-ATZ-LiK and CN-ATZ-NaK samples.

Another evidence of the improved solid state organization is found in the optical absorption. Figure $3 a$ shows that significantly enhanced optical absorption in both $\pi-\pi^{*}$ and $n-\pi^{*}$ transition regions is found for both CN-ATZ-NaK and CN-ATZ$\mathrm{LiK}$ in comparison with $\mathrm{CN}$, which also results in an evident colour change from pale yellow of $\mathrm{CN}$ to bright yellow/brownish of CN-ATZ-NaK/CN-ATZ-LiK (Figure $3 a$ inset). The $n-\pi^{*}$ electron transitions are spatially forbidden for perfectly symmetric and planar units, ${ }^{[21]}$ indicating the generation of a corrugated planar $\mathrm{CN}$ structure, which is in agreement with SEM images (Figure S5). Note that $\mathrm{CN}$ and CN-ATZ-NaK almost have no optical absorption above $650 \mathrm{~nm}$, while a strong tailing is found for CN-ATZ-LiK. Such an absorption is typical for interband transitions, for instance created by grain boundaries and similar spectrally active defects. ${ }^{[22]}$ It is still unclear to us why the $\mathrm{NaCl} / \mathrm{KCl}$ system gives higher HR-TEM order and less structure defects. The higher melting point may provide a "semiliquid-solution", supplying a reduced solubility to drive higher order. Another possibility is the exclusion of $\mathrm{Li}$ as a very small, hard ion, which may stabilize inner surfaces. The band positions of the samples changed obviously depending on diverse molten salts modifications. As shown in Figure S9, the conduction band potentials of CN-ATZ-NaK and CN-ATZ-LiK are examined to be $-0.66 \mathrm{~V}$ and $-0.2 \mathrm{~V}$ (vs. RHE) by electrochemical Mott-Schottky plots. According to the optical band gap (2.53 and $2.48 \mathrm{eV}$ ), the valence band potential can then be calculated to be 1.87 and 2.2 V for CN-ATZ-NaK and CN-ATZ-LiK, respectively. The evident downshift in the band positions in comparison with pristine $\mathrm{CN}$ $(\mathrm{VB}=1.82 \mathrm{~V}$, vs. RHE) always correlate to an enhanced degree of polymerization in the heterocyclic structure of carbon nitride, thus contributing highly stable and well-ordered structure. ${ }^{[21]}$ Apart from the optical absorption, CN-ATZ-NaK and CN-ATZ-LiK also possess more unpaired electrons in the aromatic system than $\mathrm{CN}$, as evidenced by room temperature electron paramagnetic resonance (EPR) shown in Figure 3b. Almost no change in g-value but an evident increase in the signal intensity was observed for CN-ATZ-NaK, indicating the presence of plenty of free charge carriers in the localized heterocyclic ring.
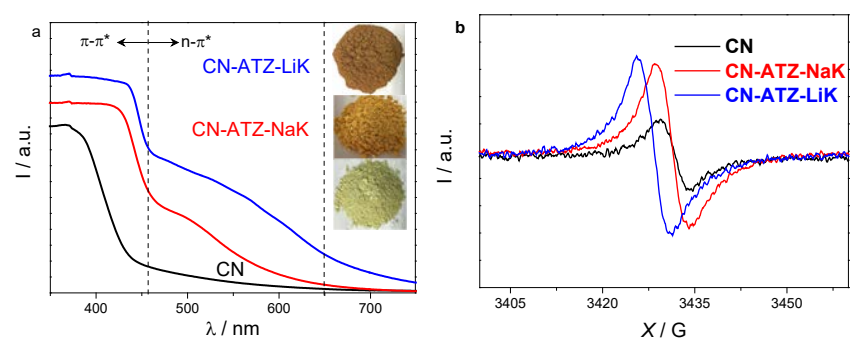

Figure 3. (a) UV-Vis optical absorption (inset: digital photograph of the asprepared samples); (b) room temperature EPR spectra of the samples.

Photocatalytic activities of the as-prepared polymers were then evaluated in a standard assay of $\mathrm{H}_{2}$ production from water under visible light irradiation (3 wt. \% $\mathrm{Pt}$ as $\mathrm{H}_{2}$ evolution cocatalyst and $10 \mathrm{~V}$. \% TEOA as electron donor). As shown in Figure $4 a$, salt melt treatment significantly improves the photocatlytic performance. In particular, CN-ATZ-NaK presents much better $\mathrm{H}_{2}$ evolution rate $\left(\mathrm{HER}=\sim 331 \mu \mathrm{mol} \mathrm{h}^{-1}\right)$ than previously prepared K-PHI (here labelled as CN-ATZ-LiK, $\sim 42$ $\left.\mu \mathrm{mol} \mathrm{h}^{-1}\right)$, pristine $\mathrm{CN}\left(\mathrm{HER}=4 \mu \mathrm{mol} \mathrm{h}^{-1}\right.$ ) and most of the previously reported salt-melt-based $\mathrm{CN}$ materials (see details in Table S3). The construction of triazine-heptazine internal heterojunction under such synthetic condition is affirmed to significantly accelerate the charge carrier transfer and thus improve the photocatalytic activity. ${ }^{[19]}$ Note that the samples obtained from $\mathrm{NaCl}\left(\mathrm{CN}-\mathrm{ATZ}-\mathrm{Na}, \mathrm{HER}=8 \mu \mathrm{mol} \mathrm{h}^{-1}\right), \mathrm{KCl}(\mathrm{CN}-$ ATZ-K, HER=7.4 $\mu \mathrm{mol} \mathrm{h}^{-1}$ ) are only slightly more active when compared to the pristine $\mathrm{CN}$, further elucidating that they do not promote recrystallization due to their melting points higher than the polymerization temperature of $550^{\circ} \mathrm{C}$. The existence of few amounts of $\mathrm{Na}$ and $\mathrm{K}$ in the sample is affirmed to change the 
electronic localization and charge carrier mobility, ${ }^{[24]}$ but the composition and property of the salt melt is also significant to improve the activities of $\mathrm{CN}$.

Beside the bare experiments, the $\mathrm{H}_{2}$ evolution performance of the material was assessed in the presence of different salts (Figure $4 \mathrm{~b}$ ). Interestingly, the $\mathrm{H}_{2}$ evolution activities of CN-ATZ$\mathrm{NaK}$ could be further boosted to $650 \mu \mathrm{mol} \mathrm{h}^{-1}$ (corresponded to apparent quantum efficiency of 0.65 ) when suitable salts (e.g., $\mathrm{K}_{2} \mathrm{HPO}_{4}$ ) were added into the reaction setup. Similar change in the $\mathrm{H}_{2}$ evolution activity could also be observed for CN-ATZ-LiK (see Figure S11).

Moreover, CN-ATZ-NaK also provides a pronounced activity at longer wavelength irradiation (Figure 4c). For instance, the performance at $465 \mathrm{~nm}$ was examined as 283 and $563 \mu \mathrm{mol} \mathrm{h}$ in the absence or presence of $\mathrm{K}_{2} \mathrm{HPO}_{4}$ respectively. This material was still active even at wavelengths of 525 and $595 \mathrm{~nm}$. Although the activities at these wavelengths are not so high due to lower driving force of the generated electron-hole pairs, it is still much higher than that of pristine $\mathrm{CN}$ at blue light. The optimized material also shows high chemical stability towards solution and light corrosion. Even after long time photocatalytic reaction, no evident decrease in the activity and no obvious structure change were examined, except for the deposition of $\mathrm{Pt}$ nanoparticles on the surface of the material coming with the testing assay (see XRD and TEM after reaction in Figure S11, 12).

In addition, the material also turned out to be active in a second assay for the photocatalytic $\mathrm{CO}_{2}$ reduction (Figure $4 \mathrm{~d}$ ), where it however created mainly $\mathrm{C}=\mathrm{O}$ as a reduction product. It should be noted that no metal cocatalysts and no organic sacrificial agents were used in this second reaction, which is conducted in a plain, economic and sustainable manner. The CO evolution activity and selectivity of this material is nevertheless much better than most of the previous carbon nitride experiments on that matter ${ }^{[23]}$ indicating the promising advantage of this salt melt strategy to synthesize photocatalysts with good properties and activities.
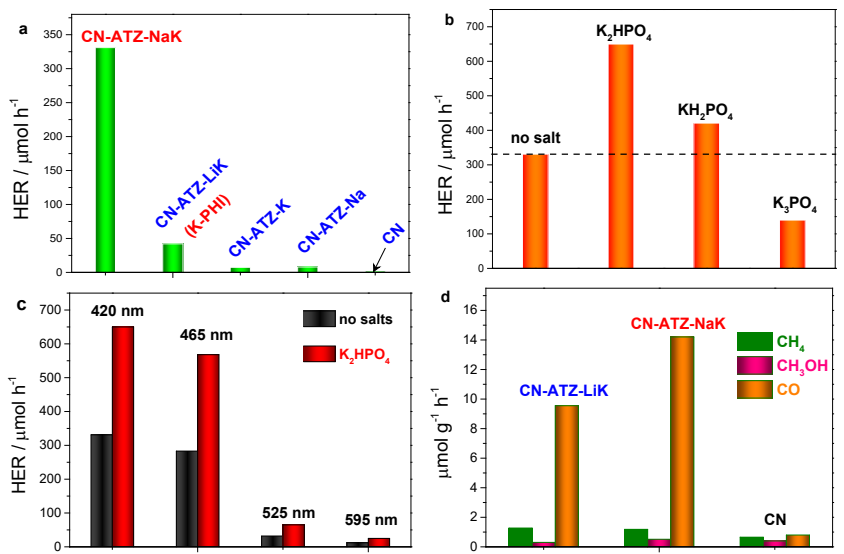

Figure 4. (a) Visible light photocatalytic $\mathrm{H}_{2}$ evolution activities of CN-ATZ prepared in the presence of different molten salts; (b) comparison activities of CN-ATZ-NaK in the presence of different salts; (c) wavelength depending $\mathrm{H}_{2}$ evolution activities of CN-ATZ-Nak; and (d) photocatalytic $\mathrm{CO}_{2}$ reduction activities of the samples.
In summary, a highly efficient photocatalyst was synthesized via a simple one-pot polymerization of a new very stable monomer, 5-amino-tetrazole in the presence of a salt mixture $(\mathrm{NaCl} / \mathrm{KCl})$ to tailor crystallinity, grain boundary structure and chemistry. The well-constructed $\mathrm{PHI}$ structure, significantly enhanced optical absorption, and optimized electronic properties are responsible for the outstanding photocatalytic performance. This study provides new idea to achieve well-organized carbon nitride with optimized properties and enhanced activities.

\section{Acknowledgements}

G. Z. thanks the Alexander von Humboldt Foundation for a postdoctoral fellowship. This work was financially supported by the Max Planck Society and the National Key R\&D Program of China (2018YFA0209301), the National Science Foundation of China (21425309 and 21761132002), and 111 project (D16008).

Keywords: Polymeric carbon nitride $\bullet$ Grain boundary $•$ Salt melt $\cdot$ Photocatalysis $\cdot \mathrm{H}_{2}$ production

[1] T. Hisatomi, J. Kubota, K. Domen, Chem. Soc. Rev. 2014, 43, 7520.

[2] M. G. Walter, E. L. Warren, J. R. McKone, S. W. Boettcher, Q. Mi, E. A. Santori, N. S. Lewis, Chem. Rev. 2010, 110, 6446.

[3] Q. Wang, T. Hisatomi, Q. Jia, H. Tokudome, M. Zhong, C. Wang, Z. Pan, T. Takata, M. Nakabayashi, N. Shibata, Y. Li, I. Sharp, A. Kudo, T. Yamada, K. Domen, Nat. Mater. 2016, 15, 611.

[4] B. A. Pinaud, J. D. Benck, L. C. Seitz, A. J. Forman, Z. Chen, T. G. Deutsch, B. D. James, K. N. Baum, G. N. Baum, S. Ardo, H. Wang, E. Miller, T. F. Jaramillo, Energy Environ. Sci. 2013, 6, 1983.

[5] J. R. Swierk, T. E. Mallouk, Chem. Soc. Rev. 2013, 42, 2357

[6] M. Bhunia, K. Yamauchi, K. Takanabe, Angew. Chem. Int. Ed. 2014, 53, 11001.

[7] Q. Han, B. Wang, Y. Zhao, C. Hu, L. Qu, Angew. Chem. Int. Ed. 2015 54, 11433.

[8] G. Liu, T. Wang, H. Zhang, X. Meng, D. Hao, K. Chang, P. Li, T. Kako, J. Ye, Angew. Chem. Int. Ed. 2015, 54, 13561.

[9] G. Zhang, G. Li, Z. Lan, L. Lin, A. Savateev, T. Heil, S. Zafeiratos, X. Wang, M. Antonietti, Angew. Chem. Int. Ed. 2017, 56, 13445

[10] D. Martin, P. Reardon, S. Moniz, J. Tang, J. Am. Chem. Soc. 2014, 136, 12568.

[11] K. Schwinghammer, B. Tuffy, M. B. Mesch, E. Wirnhier, C. Martineau, F. Taulelle, W. Schnick, J. Senker, B. Lotsch, Angew. Chem. Int. Ed. 2013, 52, 2435.

[12] X. Wang, K. Maeda, A. Thomas, K. Takanabe, G. Xin, J. M. Carlsson, K. Domen, M. Antonietti, Nat. Mater. 2009, 8, 76.

[13] J. Zhang, G. Zhang, X. Chen, S. Lin, L. Möhlmann, G. Dołęga, G. Lipner, M. Antonietti, S. Blechert, X. Wang, Angew. Chem. Int. Ed. 2012, $51,3183$.

[14] Y. Jun, J. Park, S. Lee, A. Thomas, W. Hong, G. Stucky, Angew. Chem Int. Ed. 2013, 52, 11083

[15] G. Zhang, M. Zhang, X. Ye, X. Qiu, S. Lin, X. Wang, Adv. Mater. 2014 26,805 .

[16] S. Kuecken, A. Acharjya, L. Zhi, M. Schwarze, R. Schomacker, A. Thomas, Chem. Commun. 2017, 53, 5854.

[17] a) M. Bojdys, J. Müller, M. Antonietti, A. Thomas, Chem. Eur. J. 2008 14, 8177; b) Y. Ham, K. Maeda, D. Cha, K. Takanabe, K. Domen, Chem. Asian J. 2013, 8, 218; c) E. Wirnhier, M. Döblinger, D Gunzelmann, J. Senker, B. V. Lotsch, W. Schnick, Chem. Eur. J. 2011, 17, 3213.

[18] L. Lin, H. Ou, Y. Zhang, X. Wang, ACS Catal. 2016, 6, 3921. 
[19] G. Zhang, L. Lin, G. Li, Y. Zhang, A. Savateev, S. Zafeiratos, X. Wang, M. Antonietti, Angew. Chem. Int. Ed. 2018, 57, 9372.

[20] M. Antonietti, M. Oschatz, Adv. Mater. 2018, 30, 1706836.

[21] a) I. Y. Kim, S. Kim, X. Jin, S. Premkumar, G. Chandra, N. Lee, G. P. Mane, S. Hwang, S. Umapathy, A. Vinu, Angew. Chem. Int. Ed. 2018 57, 17135; b) A. Savateev, S. Pronkin, J. Epping, M. Willinger, C. Wolff, D. Neher, M. Antonietti, D. Dontsova, ChemCatChem 2017, 9, 167.

[22] a) X. Li, G. Hartley, A. J. Ward, P. A. Young, A. F. Masters, T. Maschmeyer, J. Phys. Chem. C 2015, 119, 14938; b) Z. Wang, Y Inoue, T. Hisatomi, R. Ishikawa, Q. Wang, T. Takata, S. Chen, N Shibata, Y. Ikuhara, K. Domen, Nat. Cata. 2018, 1, 756.

[23] a) R. Kuriki, K. Sekizawa, O. Ishitani, K. Maeda, Angew. Chem. Int. Ed. 2015, 54, 2406; b) J. Qin, S. Wang, H. Ren, Y. Hou, X. Wang, Appl. Catal. B-Environ. 2015, 179, 1; c) G. Gao, Y. Jiao, E. R. Waclawik, A. Du, J. Am. Chem. Soc. 2016, 138, 6292.

[24] a) T. Xiong, W. Cen, Y. Zhang, F. Dong, ACS Catal. 2016, 6, 2462; b) A Savateev, B. Kurpil, A. Mishchenko, G. Zhang, M. Antonietti, Chem. Sci. 2018, 9, 3584 